\title{
Comparison of Body Height, Body Length, Full Length and Body Weight Growth Curves of the Longfin Batfish, Platax teira
}

\author{
Chen Zeng ${ }^{1,2}$, Baosuo Liu ${ }^{1,4}$, Kecheng Zhu',4, Liang Guo ${ }^{1,2}$, Huayang Guo ${ }^{1,4}$, Nan \\ Zhang $^{1,4}$, Quan Yang, ${ }^{1,3}$, Jing Wen Yang ${ }^{1,4}$ and Dianchang Zhang ${ }^{1,4 *}$
}

${ }^{1}$ Key Laboratory of South China Sea Fishery Resources Exploitation and Utilization, Ministry of Agriculture and Rural Affairs; South China Sea Fisheries Research Institute, Chinese Academy of Fishery Sciences, 510300, Guangzhou, Guangdong Province, China ${ }^{2}$ College of Fisheries, Tianjin Agricultural University, 300392, Tianjin, China

${ }^{3}$ National Demonstration Center for Experimental Fisheries Science Education, Shanghai Ocean University, 201306, Shanghai, China

${ }^{4}$ Guangdong Provincial Engineer Technology Research Center of Marine Biological Seed Industry, Guangzhou, Guangdong Province, China

\begin{abstract}
A B S T R A C T
To study the growth and development rules of the longfin batfish Platax teira, three nonlinear models, logistic, Gompertz and Bertalanffy, were used in the study to fit and analyse the body height, body length, full length and body weight growth curves of the fish at the age of 2-8 months. The results showed that the three nonlinear curves could fit the body height, body length, full length and body weight growth curves of the $P$. teira well, and the fitting degree was above 0.99 . Considering various factors of the models, the Gompertz model had the best fitting degree for body height, body length, full length and body weight. Under the optimal model, the monthly age of the inflection point of body height, body length, full length and body weight was $3.72,7.28,6.60$ and 8.88 , respectively; the inflection point body size or weight was $10.81 \mathrm{~cm}, 17.82 \mathrm{~cm}$ and $20.14 \mathrm{~cm}$ and $826.70 \mathrm{~g}$, respectively. The results of the experiment preliminarily revealed the growth and development rules and growth characteristics in the early stage, which provide a reference for the feeding management and feeding strategies of $P$. teira.
\end{abstract}

Article Information
Received 13 November 2019
Revised 24 December 2019
Accepted 08 January 2020
Available online 22 February 2021
Authors' Contribution
CZ, BL and DZ conceived and
designed the experiments. CZ, QY and
BL performed the experiments. CZ,
HG, NZ, LG and JWY collected the
samples. CZ analyzed the data and
wrote the paper. CZ, QY, KZ and DZ
assisted in writing and proofreading.
Key words
Platax teira, Body height, Body length,
full length, Body Weight, Nonlinear
model, Growth curve

\section{INTRODUCTION}

$\mathrm{B}^{\mathrm{a}}$ at fish Platax teira (Perciformes: Acanthuroidei: Ephippidae) also known as the long bat, is a kind of marine fish living near the shore in tropical and temperate regions. This species is native to India and occurs in the eastern Pacific, from the Red Sea and East Africa to Papua New Guinea, north to Ryukyu, and south to Australia, New Zealand and Melanesia (Bai, 2009; Golani et al., 2011). P. teira is one of the most important fin fish species in Asian aquaculture (Leu, 2018). The fish grows rapidly, juvenile fish have a beautiful shape and can be used as ornamental fish, and the meat quality of adult fish is delicious, with a high economic value and nutritional value (Liao, 2018). Adult fish grows fast, and in eight months, it can grow to about a catty, meeting the requirements of the market.

\footnotetext{
* Corresponding author: zhangdch@scsfri.ac.cn 0030-9923/2021/0002-0661 \$ 9.00/0

Copyright 2021 Zoological Society of Pakistan
}

The growth and development of animals usually have nonlinear characteristics, which can be described by a nonlinear mathematical model (Gbangboche et al., 2008). In livestock and poultry, according to the characteristics of animal growth and development, growth curve describe the growth and development rules by establishing mathematical models (Lambe et al., 2006; Aggrey, 2002; Wei et al., 2010; Yuan et al., 2012). Growth curves are often used to describe the growth and development of livestock and poultry. Nonlinear growth models commonly used in livestock and poultry include logistic, Gompertz and Bertalanffy (Arre et al., 2019; Lu et al., 2017; Yang et al., 2004). In terms of aquatic products, the growth and development of turbots have been studied with three models (Wang, 2011). Studies have also been conducted on the age and growth characteristics of largemouth Cromileptes altivelis (Ou et al., 2007). Investigations have shown that the fitting effects of different models on the growth performance of different fish species (groups) vary to a certain extent. On the other hand, the most suitable 
growth curve models were different in different families with the same month age (Wang et al., 2011). To our knowledge, there are no reports on fitting studies of the growth and development of P. teira. Therefore, in this study, the logistic, Gompertz and Bertalanffy models were used to fit the body height, body length, full length and body weight of $P$. teira with a goal of screening the growth curve fitting model of $P$. teira and identifying its growth change rules to provide a reference for improving the production performance and economic benefits of $P$. teira.

\section{MATERIALS AND METHODS}

\section{Cultivation and management of experimental fish}

In this experiment, fertilized eggs of $P$. teira were obtained from broodstock in the fishing raft. The fertilized eggs hatched in April 2018 at the Tropical Fisheries Research and Development Centre, South China Sea Fisheries Research Institute, Chinese Academy of Fishery Science, Lingshui (Hainan, China). The larvae were transferred to a 500-L fibreglass conical-shaped tank at a density of 50 larvae $\mathrm{L}^{-1}$ for cultivation. S-type rotifer and brine shrimp were used for rearing $P$. teira larvae and juveniles. The S-type rotifer was cultured as described by Leu et al. (2009). Light intensity was maintained at 2400 lux, and the light regime was controlled at $14 \mathrm{~h}$ light and $10 \mathrm{~h}$ dark. The salinity was maintained at $33 \mathrm{~g}$ $\mathrm{L}^{-1}$ throughout the experiment. The rearing temperature was $28-30^{\circ} \mathrm{C}$. Juveniles were sent to sea fishing rafts for feeding in May 2018: 10,000 juveniles of $P$. teira were kept in $3 \mathrm{~m} \times 3 \mathrm{~m}$ cages in June 2018 and September 2018, and the juveniles were divided into 5,000 and 2,500 fish in each cage. Juvenile fish were fed a diet with different nutrient levels at various stages (Table I).

Table I. Nutrition levels during the experiment.

\begin{tabular}{lll}
\hline Name & $\mathbf{2 - 5}$ months & 6-8months \\
\hline Moisture & $\leq 12$ & $\leq 12$ \\
Crude protein & $\geq 36$ & $\geq 36$ \\
Crude ash & $\leq 15$ & $\leq 15$ \\
Crude fiber & $\leq 4.0$ & $\leq 4.0$ \\
Crude fat & $\geq 5.0$ & $\geq 5.0$ \\
Total phosphorus & $0.9-1.6$ & $0.80-2.00$ \\
Lysine & $\geq 1.4$ & $\geq 1.4$ \\
\hline
\end{tabular}

\section{Phenotypic characteristic measurements}

Juvenile P. teira were first measured in June 2018. Samples were randomly drawn from the cage, and phenotypic characteristics (body height, body length, full length and body weight) were measured. A ruler and scale were used as measurement tools, and the resulting standard precision was 0.01 . Fish were fasted for a day before measurement and were anaesthetized with 100 mg/L eugenol (Shanghai Medical Instruments Co., Ltd., Shanghai, China). Using the above method, the juvenile fish were measured once a month until the end of December 2018.

\section{Statistical analysis}

According to the measurement results, Excel was used to organize traits of different ages. SPASS (22.0) was used to analyse the logistic, Gompertz and Bertalanffy models of the four traits. The classical nonlinear least squares (NLS) approach was adopted to estimate the unknown parameters of the various growth models (Hossein-Zadeh, 2015; Waiz et al., 2019). These growth models were fitted to individual animals to account for possible bias that could have arisen in the growth parameters due to consecutive and repeated measurements. The averages of the estimated parameter values and evaluation measures were then used for further analysis. The Gauss-Newton algorithm in nls2 function of the R program was utilized for the estimation of the unknown parameters (Silva et $a l ., 2012)$. The fit from each growth model was evaluated using various evaluation measures, such as, inflecting body weight or size, inflecting age, maximum monthly increase, similarity between the fitting curve and the actual curve, and the coefficient of determination $\left(\mathrm{R}^{2}\right)$. An $\mathrm{R}^{2}$ close to 1 indicates a better fit (Ganesan et al., 2015).

Using the nonlinear regression analysis fitting curve in SPSS 22.0 software, according to the different age of the body height, body length, full length and body weight data, the Gauss-Newton algorithm was used to minimize the sum of squares of residuals as the objective function. The values of each parameter were calculated in successive iterations. The convergence standard precision was 0.001 , and the iteration ended when the sum of squares of residues was less than $10^{-5}$. The optimal estimated values A, B and k were calculated by fitting, the growth model was established, the body size or weight of the inflection point and the month age of the inflection point were calculated, the growth model was evaluated according to the fitting degree $\left(\mathrm{R}^{2}\right)$ (Table II), and the growth curve was constructed by Excel (Ismail et al., 2003).

\section{RESULTS}

\section{Fitting results of the growth model}

Bertalanffy, Gompertz and logistic models were used to analyse the growth curve of $P$. teira. The results showed 
Table II. Formula and parameters of three growth growth curve models.

\begin{tabular}{llll}
\hline Models / Name & Bertalanffy & Gompertz & Logistic \\
\hline Formula & $\mathrm{W}_{\mathrm{t}}=\mathrm{A}\left(1-\mathrm{Be}^{-\mathrm{kt}}\right)^{3}$ & $\mathrm{~W}_{\mathrm{t}}=\mathrm{Ae}^{\left.-\mathrm{Bexp}^{-k \mathrm{t} t}\right)}$ & $\mathrm{W}_{\mathrm{t}}=\mathrm{A}\left(1+\mathrm{Be}^{-\mathrm{kt}}\right)^{-1}$ \\
Instantaneous growth rates & $3 \mathrm{~kW}_{\mathrm{t}}\left(\left(\mathrm{A} / \mathrm{W}_{\mathrm{t}}\right)^{1 / 3}-1\right)$ & $\mathrm{kW}_{\mathrm{t}}\left(\ln \mathrm{A}-\ln \mathrm{W}_{\mathrm{t}}\right)$ & $\mathrm{kW}_{\mathrm{t}}\left(1-\mathrm{W}_{\mathrm{t}} / \mathrm{A}\right)$ \\
Acceleration rates & $3 \mathrm{ABk}^{2} \mathrm{e}^{-\mathrm{kt}}\left(\mathrm{W}_{\mathrm{t}} / \mathrm{A}\right)^{1 / 3}\left(3 \mathrm{Be}^{-\mathrm{kt}}-1\right)$ & $\mathrm{Bk}^{2} \mathrm{~W}_{\mathrm{t}} \mathrm{e}^{-\mathrm{kt}}\left(\mathrm{Be}^{-\mathrm{kt}-1}\right)$ & $\mathrm{k}^{2} \mathrm{~W}_{\mathrm{t}}\left(1-\mathrm{W}_{\mathrm{t}} / \mathrm{A}\right)\left(1-2 \mathrm{~W}_{\mathrm{t}} / \mathrm{A}\right)$ \\
Relative growth rates & $3 \mathrm{k}\left(\left(\mathrm{A} / \mathrm{W}_{\mathrm{t}}\right)^{1 / 3}-1\right)$ & $\mathrm{kW}_{\mathrm{t}}\left(\ln \mathrm{A}-\ln \mathrm{W}_{\mathrm{t}}\right)$ & $\mathrm{k}\left(1-\mathrm{W}_{\mathrm{t}} / \mathrm{A}\right)$ \\
Inflecting body weight/measurements & $8 \mathrm{~A} / 27$ & $\mathrm{~A} / \mathrm{e}$ & $\mathrm{A} / 2$ \\
Inflecting age & $(\mathrm{In} 3 \mathrm{~B}) / \mathrm{k}$ & $(\mathrm{InB}) / \mathrm{k}$ & $(\mathrm{InB}) / \mathrm{k}$ \\
Maximum monthly increase & $\mathrm{kW} / 2$ & $\mathrm{~kW}$ & $3 \mathrm{~kW} / 2$ \\
\hline
\end{tabular}

A is Mature body weight; B is Parameter of day-age; $\mathrm{k}$ is Instant growth rate; $\mathrm{t}$ is Age of the month; $\mathrm{W}$ is Inflection point body size or weight; $\mathrm{W}_{\mathrm{t}}$ is body size or weight at $t$ months of age

Table III. Three nonlinear growth curve models and parameter fitting results.

\begin{tabular}{lllllllll}
\hline Name & Models & A & B & $\mathbf{k}$ & $\mathbf{R}^{2}$ & $\begin{array}{l}\text { Inflecting body } \\
\text { weight/size }\end{array}$ & $\begin{array}{l}\text { Inflectin- } \\
\text { gage }\end{array}$ & $\begin{array}{l}\text { Maximum monthly } \\
\text { increase }\end{array}$ \\
\hline Body height $(\mathrm{cm})$ & Bertalanffy & 32.441 & 0.515 & 0.159 & 0.993 & 9.61 & 2.74 & 0.76 \\
& Gompertz & 29.375 & 1.988 & 0.210 & 0.992 & 10.81 & 3.72 & 2.27 \\
& Logistic & 25.102 & 4.373 & 0.362 & 0.991 & 12.55 & 4.08 & 6.81 \\
Body length (cm) & Bertalanffy & 70.079 & 0.605 & 0.069 & 0.996 & 20.76 & 8.64 & 0.72 \\
& Gompertz & 48.426 & 2.379 & 0.119 & 0.995 & 17.82 & 7.28 & 2.12 \\
& Logistic & 31.676 & 5.528 & 0.269 & 0.995 & 15.84 & 6.36 & 6.39 \\
Full length (cm) & Bertalanffy & 78.192 & 0.598 & 0.076 & 0.990 & 23.168 & 7.69 & 0.88 \\
& Gompertz & 54.732 & 2.342 & 0.129 & 0.990 & 20.14 & 6.60 & 2.60 \\
Body & Logistic & 36.166 & 5.409 & 0.292 & 0.991 & 18.08 & 5.78 & 7.91 \\
weight $(\mathrm{g})$ & Bertalanffy & 12953.443 & 0.989 & 0.057 & 0.995 & 3838.06 & 19.08 & 109.38 \\
& Gompertz & 2246.974 & 7.053 & 0.220 & 0.996 & 826.70 & 8.88 & 181.87 \\
& Logistic & 947.46 & 121.601 & 0.705 & 0.998 & 473.73 & 6.81 & 500.97 \\
\hline
\end{tabular}

that the fitting degree of body height, body length, full length and body weight of the three growth model curves were all above 0.990 (Table III). All three models accurately simulated the growth curves of body height, body length, full length and body weight. However, taking into account the age at the inflection point, the weight at the inflection point, the maximum monthly growth and the limit growth of the three models, the Gompertz model best simulated body height, body length, full length and body weight; the fitting degree $\left(\mathrm{R}^{2}\right)$ was $0.992,0.995,0.990$ and 0.996 , respectively; the limit growth volume (A) was $29.375,48.426,54.732$ and 947.456; the monthly age of the inflection point was $3.27,7.28,6.60$ and 8.88; and the body size or weight of the inflection point was 10.81 , 17.82, 20.14 and 826.70; and limit growth rate $(\mathrm{k})$ was $0.210,0.119,0.129$ and 0.220 .

\section{Comparative analysis of the growth curve model}

The simulated predicted values of the body height, body length, full length and body weight of the fish were compared with the measured values. The results showed that the three growth curve models showed little difference in the values of body height, body length, full length and body weight and well reflected the early growth and development rules of $P$. teira. However, considering various factors, the Gompertz model had the best fitting degree for body height, body length, full length and body weight. The difference between the predicted value and the measured value of body height was $0.08-0.72 \mathrm{~cm}$, that of body length was $0.06-0.38 \mathrm{~cm}$, that of full length was $0.01-0.84 \mathrm{~cm}$, and that of body weight was $3.25-25.75$ g. To study the direct relationship between the measured value and the predicted value of the three models more intuitively, the growth curve of the predicted value of the three models and the measured value curve were drawn in this experiment for comparison ( $\mathrm{Gu}$ et al., 2019; Zhang et al., 2006; Zhu et al., 2006; Xiao et al., 2008) (the three model curves and measured value curves of body height, body length, full length and body weight are shown in (Fig. 1). The predicted value curves of body height, body length, full length and body weight of the three models were almost identical, among which the measured value 
curves of body height were lower than the predicted value curves of the three models at 2-3 months old, significantly higher than the predicted value curves of the three models at 3-5 months old, and essentially identical with the predicted value curves of the three models at 3-8 months old. Except that the measured curves of body length were higher than the predicted curves of the three models at 3-4 months old, the other monthly curves were almost identical with the three models. The full-length measured value curves were higher than those of the three model curves at the ages of 2-4 months and 6-8 months, and lower than the three model curves at the ages of 4-6 months. The measured value curve of body weight was higher than that of the three predicted value curves at the age of 2-4 months and almost the same as those with the three predicted value curves from June to August.
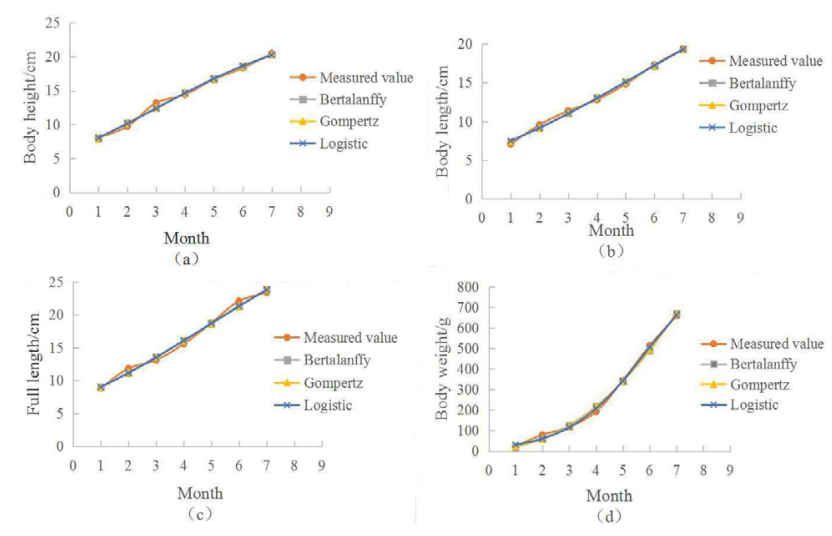

Fig. 1. Three model measured value and prediction curves for body height (a), body length (b), full length (c) and body weight $(\mathrm{d})$.
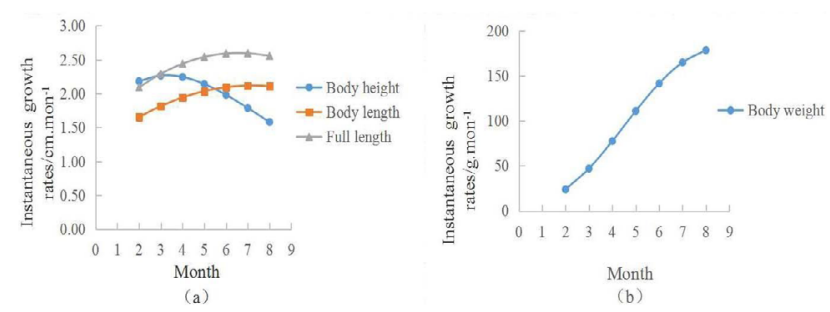

Fig. 2. Instantaneous growth rates of body height, body length and full length (a) and body weight (b).

Growth and development rules of body height, body length, full length and body weight of the Gompertz model

Of the three kinds of models, the Gompertz model better predicted the $P$. teira in terms of body height, body length, full length and body weight growth curves, To more comprehensively understand the $P$. teira growth rule, the Gompertz model growth curves of body height, body length, full length and body weight were calculated, showing the instantaneous growth rate (Wang et al., 2014) (Fig. 2), the instantaneous growth acceleration rate (Chen et al., 2006) (Fig. 3) and the relative growth rate (Li et al., 2008) (Fig. 4).
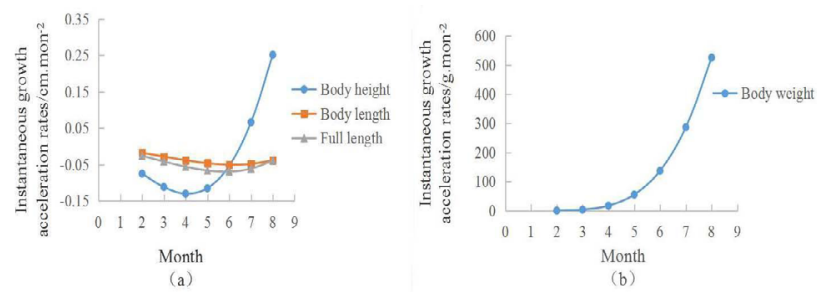

Fig. 3. Instantaneous growth acceleration rates of body height, body length and full length (a) and body weight (b).

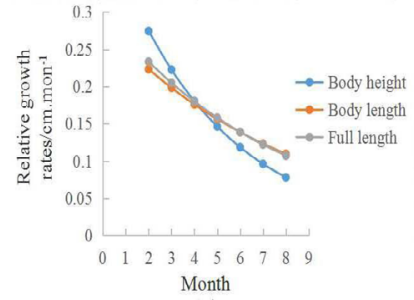

(a)

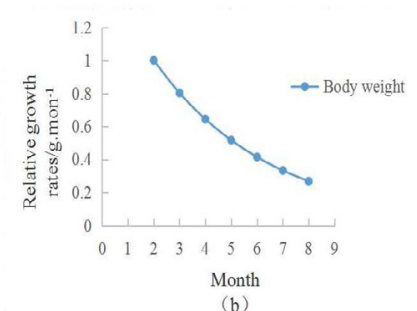

b)
Fig. 4. Relative growth rates of body height, body length and full length (a) and body weight (b).

In Figure 2, the vertex of the instantaneous growth rate curve was the inflection point of each trait curve. Before the inflection point, all traits showed an accelerating growth state, while after the inflection point, all traits showed a decelerating growth state. That is, before the inflection point, the instantaneous growth rate gradually increased until the maximum value at the inflection point. After the inflection point, the instantaneous growth rate gradually decreased. At 2-8 months, the instantaneous growth rate of body height, body length, and full length showed a decreasing trend after the first increase, but the instantaneous growth rate increase and decrease of time were not identical. The body height instantaneous growth rate at 2-3 months increased, peaked at 3 months, and then showed a declining trend: body length and full length instantaneous growth rates increased and decreased from 2 to 7 months, and at seven months, they reached a maximum instantaneous growth rate, showing a downward trend after 7 months. The instantaneous growth rate of body weight at 2-8 months increased, indicating that the growth rate of the body weight accelerated, which is consistent with the results of the Gompertz model growth curve of body weight in Figure 1. Body height, body length 
and full length instantaneous growth rates accelerated first and decreased with increasing trends; body height and body length fluctuations were small; the full length of volatility was large; the full length of the accelerating production rate of the instantaneous growth rate in 5-8 months showed an obvious increase; body height instantaneous growth accelerated rate increased from 2 to 8 months, showing that the body weight grew at an accelerating speed. The relative growth rates of body height, body length, full length and body weight decreased at 2-8 months old, and the relative growth rate of body weight decreased the fastest.

\section{DISCUSSION}

\section{Comparative analysis of growth curves}

The logistic, Gompertz and Bertalanffy models are mainly used to study the growth rules of livestock, and some reports have been conducted on aquatic products (Ou et al., 2007; Wang, 2011). The advantages and disadvantages of the fitting effect of the mathematical model are represented by the fitting degree $R^{2}$, and its size represents the degree of reliability of the regression equation of the mathematical model (Li, 2014; Fuping, 2019; Hamoudaa et al., 2011; Hojjati et al., 2018). The closer $\mathrm{R}^{2}$ is to 1 , the better the fitting degree of the regression equation to the predicted value; conversely, the smaller $\mathrm{R}^{2}$ is, the worse the fitting degree of the regression equation to the predicted value. In this study, logistic, Gompertz and Bertalanffy curve models were used to fit the growth curves of the body height, body length, full length and body weight of the $P$. teira, and the fitting degree of the three models was above 0.99 , indicating that the three models well simulated the growth curves of the body height, body length, full length and body weight of the $P$. teira. In comparison to the results of the curve fitting and measured values, the Gompertz model simulated the degree of body height, body length, full length and body weight best. Different growth curve fitting models have different characteristics, and different species of fish have different growth rules; thus, the optimal curve fitting model selected by different species of fish will be different, and the suitable model selected for different species is conducive to understanding their growth and development rules. In this study, the fitting degree of the Gompertz model growth curves for body height, body length, full length and body weight were $0.992,0.995,0.990$ and 0.996 , respectively; the monthly age of the inflection point was $3.72,7.28,6.60$ and 8.88, respectively; the inflection points of the body size or weight were $10.81 \mathrm{~cm}, 17.82 \mathrm{~cm}$, $20.14 \mathrm{~cm}$ and $826.70 \mathrm{~g}$, respectively. Of the growth curves of the other models, those of the Gompertz model better reflected the development rules of the body height, body length, full length and body weight of the longfin batfish at the age of 2-8 months and can be used to predict the growth and development of the longfin batfish at the later stage. At the same time, according to the development law of the longfin batfish in the early stage, the nutrition ratio in the feed can be reasonably distributed, and an appropriate feeding program can be formulated, which is helpful for managing and improving the economic benefits of the breeding process.

\section{Growth and development law analysis}

Body height, body length, full length and body weight are important indicators of fish development. The longfin batfish is a special kind of fish. In the early stage of its development, its body length is longer than its body length. With growth and development in the later stage, its body length gradually exceeds its body height. The growth curves of the logistic, Gompertz and Bertalanffy models are all cumulative growth curves and do not reflect the change in growth rate at a certain moment, while the instantaneous growth rate and relative growth rate can well describe growth changes (Wang et al., 2011). According to the instantaneous growth rate curve (Fig. 2), the instantaneous growth rate of body height increased at 2-3 months old and decreased at 3-8 months old, indicating that the growth rate of the body height accelerated at 2-3 months old and decreased at 3-8 months old. The instantaneous growth rate of body length and full length remained the same. The instantaneous growth rate increased continuously during 2-7 months old and reached a maximum at 7 months old. After 7 months, the growth rate began to decrease. The instantaneous growth rate of the body weight increased continuously from the age of 2 months, indicating that the instantaneous growth rate of body weight increased in speed. The relative growth rates of the body height, body length, full length and body weight decreased from the age of 2 months (Fig. 4). The relative growth rates of body weight all decreased the fastest, and the relative growth rates of body height before the age of 4 months were lower than those of body length and full length, and after the age of 4 months, they were higher than those of body length and full length.

Reference value of the growth curve fitting results for feeding management

Various factors affect the growth and development of animals (Zhang et al., 2009). The influence of not only genetic factors but also environmental factors, such as nutrition, feeding strategy, water environment and feeding management, will affect the shape of growth curves. Therefore, the fitting effect of the same curve model under different influencing factors is also different. The same 
model, the simulation results of different characteristics on the same individual, is also different, such as the trial with body height, body length, full length and body weight of the best Gompertz model simulation degree, simulating the growth curve, instantaneous growth rate curve, instantaneous growth accelerated rate curve and relative growth rate curve, which were not identical; the four characteristics were not identical for the longfin batfish during the allometric growth relationship (Liu et al., 2008; Zhang et al., 2017). Therefore, the results of this experiment are only of reference value for the early growth and development of longfin batfish. In the production process, breeding and management strategies should be reasonably formulated according to the actual situation.

\section{CONCLUSION}

In this study, logistic, Gompertz and Bertalanffy models of three growth curve models were used to fit the body height, body length, full length and body weight growth curves of $P$. teira. The fitting degree was greater than 0.990 , which indicated that it could well simulate the growth curves of body height, body length, full length and body weight. Of the models, the Gompertz model best simulated body height, body length, full length and body weight by integrating many factors, such as growth limit, month age at the inflection point, weight at the inflection point and maximum monthly weight gain. This experiment preliminarily revealed the growth rules and characteristics of the early development of the longfin batfish and has certain significance for the management and feeding strategies related to the breeding process of the longfin batfish.

\section{ACKNOWLEDGEMENT}

This work was supported by the National Key R\&D Program of China (2018YFD0901204), Fund of Key Laboratory of South China Sea Fishery Resources Exploitation and Utilization, Ministry of Agriculture and Rural Affairs(FREU2018-01), the Guangdong Provincial Science and Technology Project (2019B030316030), the China-ASEAN Maritime Cooperation Fund and the National Infrastructure of Fishery Germplasm Resources Project (2019DKA30470).

\section{Statement of conflict of interest}

The authors have declared no conflict of interests regarding the publication of this article.

\section{REFERENCE}

Aggrey, S.E., 2002. Comparison of three nonlinear and spline regression models for describing chicken growth curves. Poult. Sci., 81: 1782-1788. https:// doi.org/10.1093/ps/81.12.1782

Arre, F.A., Campelo, J.E.G., Rocha, J. L., Sarmento, L.A.S.F. and Cavalcante, D.H., 2019. A comparison of nonlinear models for describing weight-age data in Anglo-Nubian does. Rev. Caatinga, 32: 251-258. https://doi.org/10.1590/1983-21252019v32n125rc

Bai, M., 2009. Marine ornamental fish. Chemical Industry Press, Beijing.

Chen, D.Q., Zhang, X., Xiong, F., Liu S.Q. and Tang, H.Y., 2006. Growth characteristics of naked carp in Qinghai lake. Acta Hydrobiol. Sin., 2: 173-179.

Fuping, 2019. Study on growth curve fitting of slow feather line of Guizhou yellow chicken. China Anim. Husb. Vet. Med., 46: 2053-2058.

Ganesan, R., Danavanthan, P., Balasubramanyam, D., Kumarasamy, P. and Kiruthika., 2015. Growth modeling and factors affecting growth traits in Madras red sheep. Indian. J. Anim. Res., 49: 20-25. https://doi.org/10.5958/0976-0555.2015.00004.7

Gbangboche, A.B., Gleke-Kalai, R., Albuquerque, L.G. and Leroy, P., 2008. Comparison of non-linear growth models to describe the growth curve in West African dwarf sheep. Animal, 2: 1003-1012. https://doi.org/10.1017/S1751731108002206

Golani, D., Sonin, O. and Edelist, D., 2011. Second records of the Lessepsian fish migrants Priacanthus sagittarius and Platax teira and distribution extension of Tylerius spinosissimus in the Mediterranean. Aquat. Invas., 1: S7-S11. https:// doi.org/10.3391/ai.2011.6.S1.002

Gu, L.Q., Liao, S.Q., Zhou, Q.X., Xu, T.S, Ye, B.G., Yang, S.X., Xing, M.Q. and Lin Z.M., 2019. Growth curve analysis of different geese. Heilongjiang Anim.Husb. Vet. Med., 4: 48-51+179.

Hamoudaa, M.B. and Atti, N., 2011. Comparison of growth curves of lamb fat tail measurements and their relationship with body weight in babarine sheep. Small Rumin. Res., 95: 120-127. https://doi. org/10.1016/j.smallrumres.2010.10.001

Hojjati, F. and Hossein-Zadeh, N.G., 2018. Comparison of non-linear growth models to describe the growth curve of Mehraban sheep. J. appl. Anim. Res., 46: 499-504. https://doi.org/10.1080/09712119.2017.1 348949

Hossein-Zadeh, N.G., 2015. Modeling the growth curve of Iranian Shall sheep using non-linear growth models. Small Rumin. Res., 130: 60-66. https://doi. org/10.1016/j.smallrumres.2015.07.014

Ismail, Z., Khamis, A. and Jaafar, M.Y., 2003. Fitting nolinear Gompertz curve to tobacco growth data. 
Pak. J. Agron., 2: 223-236. https://doi.org/10.3923/ ja.2003.223.236

Lambe, N.R., Navajas, E.A., Simm, G. and Bünge. L., 2006. A genetic investigation of various growth models to describe growth of lambs of two contrasting breeds. J. Anim. Sci., 84: 2642-2654. https://doi.org/10.2527/jas.2006-041

Leu, M.Y., Liou., C.H., Wang, W.H., Yang, S.D. and Meng, P.J., 2009. Natural spawning,early development, and first feeding of the semicircle angelfish [Pomacanthus semicirculatus (Cuvier, 1831)] in captivity. Aquacul. Res., 40: 1019-1030. https://doi.org/10.1111/j.1365-2109.2009.02192.x

Leu, M.Y., Taic, K.Y., Meng, P.J., Tang, C.H., Wang P.H. and Tewa, K.S., 2018. Embryonic, larval and juvenile development of the longfin batfish, Platax teira (Forsskål, 1775) under controlled conditions with special regard to mitigate cannibalism for larviculture. Aquaculture, 439: 204-213. https:// doi.org/10.1016/j.aquaculture.2018.05.006

Li, H., Rao, Y.C., Mu, T.H., Yang, D.F., Jian, H.F., Lin, J.D., Li, Z.Q., Ou, Y.S., Wu, X.P., Dai, Y.G. and Hu, H.G., 2008. Growth characteristics of eel in poyang lake. J. Zool., 3: 113-120.

Li, J.Y., Zhan, K. and Yang, X.J., 2014. Study on body weight growth and development of huangshan black chicken. Chinese J. Southw. Agric., 27: 12951299.

Liao J., 2018. Artificially bred the longfin batfish Platax teira with high cost performance and can be fed with artificial compound feed for ornamental consumption. Oceans Fish., 11: 62-63.

Liu, Y.J., Cheng, D.C., Zhou, S.J., Ma, Z.H., Hu, J. and Yang, R., 2008. Studies on the allelic growth of young perch and young perch. Mar. Fish., 40: 179-188.

Lu, X.L., Zhao, L.L. and Li, H.J., 2017. Pudong chicken growth curve fitting and analysis and comparison. China Poult., 39: 53-55.

Ou, Y.J., Liao, R., and Li, J.R., 2007. Age and growth characteristics of lateolus humpback. Acta Fish. Sin., 31: 624-632.

Silva, L.S.A.D., Fraga, A.B., Silva, F.D.L.D., Beelen, P.M.G., Silva, R.M.D.O., Tonhati, H. and Barros, C.D.C., 2012. Growth curve in Santa Inês sheep. Small Rumin. Res., 105: 182-185. https://doi. org/10.1016/j.smallrumres.2011.11.024

Waiz, H.A., Gautam, L. and Waiz, S.A., 2019. Appraisal of growth curve in Sirohi goat using non-linear growth curve models. Trop. Anim. Hlth. Pro. 51: 1135-1140. https://doi.org/10.1007/s11250-01801794-X

Wang, X.A., Ma, A.J., Huang, ZH., Ma, D.Y., Wang, T., Tian, Y.Q., Wang, G.N. and Qu, J.B., 2014. Growth and development differences of male and female populations in breeding families of turbot. Acta Fish. Sin., 38: 464-469.

Wang, X.A., Ma, J., Huang, Z.Z., Liu, Q. M., Guo, L.,Yang, Z. and Qu, J.B., 2011. Growth and development rules of fine families bred by largescale breeding of turbot. Mar. Lacustrine, 42: 266273.

Wei, C.X., Sun, S.Y. and Wu, C.Q., 2010. Quality determination and correlation analysis of lingkun eggs. Poult. Sci., 8: 39-40.

Xiao, S.H., Wen, T. and Yu, D.B., 2008. Growth curve fitting and comparative analysis of cherry valley duck. Anim. Husb. Vet. Med., 40: 45-47.

Yuan, F., Luo, H.L. and Chen, L., 2012. Study on early growth curve fitting of nanjiang yellow sheep. Chinese J. Anim. Husb., 48: 15-18.

Yang, H.M., Xu, Q. and Dai, G.J., 2004. Analysis of three common growth curves of poultry. Chinese Poult., 1: 164-166.

Zhang, G.Z., Jiang, J.F., Song, X.M., Zhou, W.D., Huang, X., Zheng, H.C., Shi,F.X. and Jiang, Y.Q., 2009. Fitting of early growth curve of hu sheep. Anim. Husb. Vet. Med., 41: 31-34.

Zhang, H., Gong, D. and Z.J., 2006. Study on growth curve analysis and fitting of liyang chicken. Anim. Husb. Vet. Med., 38: 7-9.

Zhang, Y.L., Zhang, H.L., Wang, L.Y., Gu, B.Y. and Fan, Q.-X., 2017. Research progress on allelic growth and changes of nucleic acid and digestive enzymes in early development stage of fishes. Chinese Fish. Sci., 24: 648-656. https://doi.org/10.3724/ SP.J.1118.2017.16210

Zhu, Z.M., Qiang, B.Z., Zhu, Q.F., Ji, S.L., Tang, X.H., Magdalen. and Liu, B., 2006. Comparative study on growth curve fitting and analysis of Tibetan chicken. Chinese Agric. Sci., 10: 2159-2162. 